\title{
System design of the temperature measurement and control in furnace for steel mill and its data fitting and analysis
}

\author{
Yu-Hang Huang and Xing-Fang Jiang \\ Changzhou College of Information Technology, Changzhou, 213164, China \\ School of Mathematics and Physics, Changzhou University, Changzhou, 213164, China \\ E-mail: weehouse6611@eyou.com,xfjiang@cczu.edu.cn
}

\begin{abstract}
For the problems of the temperature measurement and control system in steel mill, a temperature measurement and control system based on single chip microcomputer has been designed. The problems are defects in low precision of temperature measurement and large drift of temperature controlling. The designed system includes hardware circuit and software design and it is suitable for temperature controlling of smelting special steel furnace in steel mill. The fitting curve and the analysis result obtained based on the actual measured data. The result shows that the error between the actual measured data and the fitting calculation data is $0.1^{\circ} \mathrm{C}$. The system has functions of the real-time detection, display, and over-temperature-alarm.
\end{abstract}

Keywords: Thermocouple; Temperature Control; Circuit Design; Data Fitting.

\section{Introduction}

The furnace temperature controlling in the process of the furnace temperature measurement for smelting special steel in steel mill includes the process temperature controlling and end temperature controlling. In them the process temperature controlling is very difficult. The temperature fluctuation of molten steel is large if the temperature does not control. In the previous control system, the method of point by point measurement has been used and the controlling method is single method. An idea based on single chip microcomputer had been envisaged. The comparing between the stored data and the data of fitting curve could be worked in the new system. The heater would be started if the stored data is less than that of fitting curve. Based on this analysis, the team has developed a system for the steel furnace temperature measurement and control based on the thermocouple. The thermocouple is suit for the measurement of the special steel smelting temperature with the ultra-high temperature environment and realizes the precise controlling of the furnace temperature [1]. 


\section{Design Scheme}

\subsection{Design idea}

The purpose of the system design is for overcoming the defects in the process of smelting special steel temperature measurement and controlling in steel mill. A system of temperature measurement and controlling has been developed based on single chip microcomputer. It could obtain accurately the temperatures in the measured area with point distribution temperature measuring method in the field and a number of average temperatures have been obtained. If the measure temperature is below a range of the stored curve the measured area would start heater for continuous heating then would keep with constant temperature [2]. The precision of the temperature sensor is $1^{\circ} \mathrm{C}$ and the temperature measurement range is $0^{\circ} \mathrm{C} \sim 1800{ }^{\circ} \mathrm{C}$.

The temperature drift of the thermocouple is very low; it reaches below 1 $\mu \mathrm{V}$ per degree and the stability is good [3]. The switching time of up to $500 \mu \mathrm{s}$ with electronic solid state relay (SSR) as the load and it is controlled by chopping; it is quick response, so that it is suit for the accurate debug heating mode. The varied pulse duty ratio is used for adjusting the heating time and the heating frequency for ensuring the precision of controlling temperature [4].

\subsection{Hardware section of system circuit}

\subsubsection{Black diagram}

This device includes CPU module (STM32F407) that is used for controlling the work of the whole furnace temperature. The controlling process includes the collected data that is from thermocouple 1 reflects the size of the furnace temperature after A/D conversion. The outputted current signal 4 20 mA is for analog display instrument. The outputted over high-temperature alarm signal is into the driver circuit. The block diagram is as shown in figure 1.

\subsubsection{Sensors and compensation circuit}

The selected sensor is Platinum Rhodium 10- Platinum thermocouple sensor and its measured temperature range of $0 \sim 1800^{\circ} \mathrm{C}$. The bridge compensation method is adopted as cold end compensation and it compensates the fluctuations of the thermoelectric emf caused by temperature change in cold end through the emf produced from unbalanced bridge. The unbalanced bridge consists of resistors of four bridge arm $R_{1}-1, R_{2}-1, R_{3}-1, R_{\mathrm{cu}}-1$, and regulated power supply in bridge road as shown in figure 2 . 


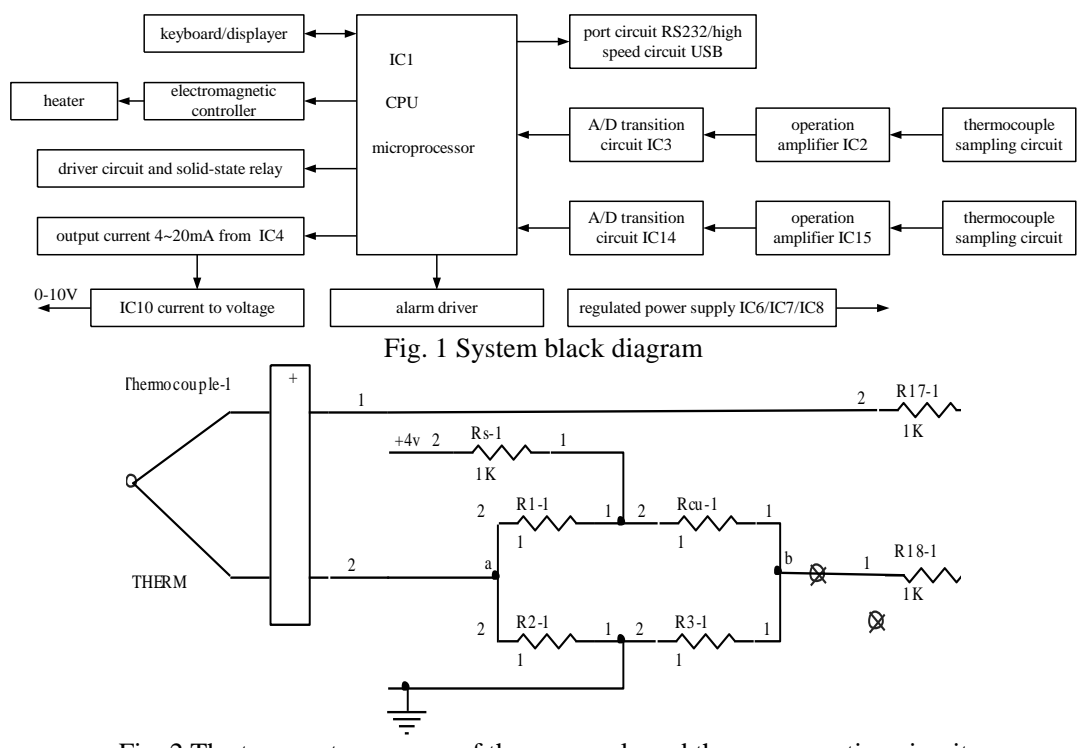

Fig. 2 The temperature sensor of thermocouple and the compensation circuit

\subsubsection{Single chip microcomputer control circuit}

The single chip microcomputer circuit of IC1 (STM32F407RDT6) is with 32 bits and it used advance Cortex-M4 kernel. It can be done within the FFT, all kinds of filtering, signal compression, and recognition. It is with multiple bus parallel processing capabilities such as input external high-speed Ethernet, highspeed USB, two general DMA ways. At the same time it drives LCD screen with output of audio signal. This circuit has the ultra low power and the power consumption is only $38.6 \mathrm{~mA}$ when the frequency is $168 \mathrm{MHz}$ [5].

\section{Fitting Theory Method and the Result Analysis Sub-Headings}

Due to the relation between the thermocouple sensor of temperature with the thermoelectric emf is not a single linear function. In order to improve the effectiveness of the system in programming, the temperature range must be found. In the temperature range the relation between the thermocouple sensor of temperature with the thermoelectric emf is an approximate linear function. It is very beneficial for computing and programming.

The Least Square Method is used to the selected thermocouple of platinumrhodium 10 - platinum for curve fitting for determining the ratio parameter of the thermocouple temperature measurement and thermoelectric potential. The 
temperature ranges are over whole thermocouple measuring range. The space of the fitting point is $1^{\circ} \mathrm{C}$ and the maximum fitting error is not more than $0.1{ }^{\circ} \mathrm{C}$.

\subsection{The basic theory of the fitting}

It supposes the relationship between the thermocouple temperature $T$ and the thermoelectric emf $E$ is $T=T(E)$. For $T_{\mathrm{n}}$ the corresponding thermoelectric emf is $E_{n},(n=0,1, \ldots)$ and the temperature range is $-50 \sim 1800{ }^{\circ} \mathrm{C}$. The function $T=T(E)$ is not a single linear function and it can be used m-order polynomial as fitting function. The Least Square Method can use to fit curve for the $n+1$ nodes [12]. It supposes

$$
T=T(E)=f_{m}(E)=a_{0}+a_{1} E+a_{2} E^{2}+\ldots+a_{m} E^{m}, m<n-1
$$

here $a_{j}(j=0,1,2, \ldots, m)$, for $E_{i}(i=0,1,2, \ldots, n)$ the sum of the error square is

$$
\delta=\sum_{i=0}^{n}\left[f_{m}\left(E_{i}\right)-T_{i}\right]^{2}=\sum_{i=0}^{n}\left[a_{0}+a_{1} E_{i}+a_{2} E_{i}^{2}+\ldots+a_{m} E_{i}^{m}-T_{i}\right]^{2}
$$

The partial derivative of the sum of the error square for $a_{j}$ is zero.

$$
\partial \delta / \partial a_{j}=0,(j=0,1,2, \ldots, m)
$$

The matrix form is as

$$
\left[\begin{array}{cccc}
\sum_{i=0}^{n} 1 & \sum_{i=0}^{n} E_{i} & \ldots & \sum_{i=0}^{n} E_{i}^{m} \\
\sum_{i=0}^{n} E_{i} & \sum_{i=0}^{n} E_{i}^{2} & \ldots & \sum_{i=0}^{n} E_{i}^{m+1} \\
\ldots & \ldots & \ldots & \ldots \\
\sum_{i=0}^{n} E_{i}^{m} & \sum_{i=0}^{n} E_{i}^{m+1} & \ldots & \sum_{i=0}^{n} E_{i}^{2 m}
\end{array}\right]\left[\begin{array}{c}
a_{0} \\
a_{i} \\
\ldots \\
a_{m}
\end{array}\right]=\left[\begin{array}{c}
\sum_{i=0}^{n} T_{i} \\
\sum_{i=0}^{n} E_{i} T_{i} \\
\ldots \\
\sum_{i=0}^{n} E_{i}^{m} T_{i}
\end{array}\right]
$$

\subsection{The steps for curve fitting formula}

(1) To determine the maximum fitting error in each node (The default value is $0.3^{\circ} \mathrm{C}$ ) and the fitting temperature range is $-50 \sim 1800^{\circ} \mathrm{C}$.

(2) To list the equations (9) and to solve each element of the coefficient matrix then to decide the equation (6).

(3) To check the fitting error

(a) If the error is too large it would recalculate with more number of fitting polynomial or decreasing the temperature range.

(b) If the error is too small it would recalculate with increasing the temperature range.

(c) If the error is normal it would execute the next internal fitting. 
(d) If the range does not increase or there is no next range the calculation process is end.

\subsection{Analysis of the calculation result}

The polynomial calculation of the indexing table for Platinum Rhodium 10Platinum thermocouple and its result based on the criterion of IEG584-1 and GB3772-83 are following.

The calculation formula of emf with the temperature $\mathrm{T}$.

$E=5.394467 T^{1}+1.241976 \times 10^{-2} T^{2}-2.234813 \times 10^{-5} T^{3}+2.835217 \times 10^{-8} T^{4}$ for $-50 \sim 629^{\circ} \mathrm{C}$;

$E=-2.882337 \times 10^{2}+8.227554 \times 10^{0} T^{1}+1.635382 \times 10^{-3} T^{2}$ for $630 \sim 1064^{\circ} \mathrm{C}$;

$E=1.3843437 \times 104+3.6378679 \times 10^{3}\left(\frac{T-1365}{300}\right)^{1}-5.0271203 \times 10^{0}\left(\frac{T-1365}{300}\right)^{2}-4.2450448 \times 10^{1}\left(\frac{T-1365}{300}\right)^{3}$ for $1065 \sim 1665^{\circ} \mathrm{C}$;

$E=1.8113086 \times 10^{4}+5.6785365 \times 10^{2}\left(\frac{T-1715}{50}\right)^{1}-1.2112390 \times 10^{1}\left(\frac{T-1715}{50}\right)^{2}-2.7117587 \times 10^{1}\left(\frac{T-1715}{50}\right)^{3}$
$1666 \sim 1767^{\circ} \mathrm{C}$ for $1666 \sim 1767^{\circ} \mathrm{C}$;

The calculation formula of the fitting results for the temperature were $T=1.752109 \times 10^{2} E^{1}-8.140778 \times 10^{1} E^{2}+1005997 \times 10^{2} E^{3}-1.142815 \times 10^{2} E^{4}$ for $-50 \sim 159^{\circ} \mathrm{C}$ and the maximum error is $8.814323 \times 10^{-2}{ }^{\circ} \mathrm{C}$

$T=1.7113011 \times 10^{3} E^{1}-2.850047 \times 10 E^{2}+3.051468 \times 10^{0} E^{3}+1.744674 \times 10^{0} E^{4}+1.401330 \times 10^{-1} E^{5}$

for $160 \sim 374^{\circ} \mathrm{C}$ and the maximum error is $5.588478 \times 10^{-2}{ }^{\circ} \mathrm{C}$

$T=1.548615 \times 10^{2} E^{1}-1.574068 \times 10 E^{2}+2.211235 \times 10^{0} E^{3}-1.447084 \times 10^{-1} E^{4}$ for $375 \sim 687^{\circ} \mathrm{C}$

and the maximum error is $8.347254 \times 10^{-2}{ }^{\circ} \mathrm{C}$

$T=1.334814 \times 10^{-3} E^{1}-4.372191 \times 10^{0} E^{2}+1.4000015 \times 10^{-1} E^{3}$ for $688 \sim 850^{\circ} \mathrm{C}$ and the maximum error is $8.188712 \times 10^{-2}{ }^{\circ} \mathrm{C}$

$T=8.061312 \times 10^{1} E^{1}+1.285153 \times 10^{1} E^{2}-1.512701 \times 100 E^{3}+6.279972 \times 10^{-2} E^{4}-1.179356 \times 10^{-2} E^{5}$ for $851 \sim 999^{\circ} \mathrm{C}$ and the maximum error is $3.100488 \times 10^{-2}{ }^{\circ} \mathrm{C}$

$T=9.722175 \times 10^{1} E^{1}+8.318394 \times 10^{1} E^{2}-1.512908 \times 10^{0} E^{3}+9.617005 \times 10^{0} E^{4} \quad$ for

$1000 \sim 1224^{\circ} \mathrm{C}$ and the maximum error is $5.587614 \times 10^{-2}{ }^{\circ} \mathrm{C}$

$T=1.282868 \times 10^{2} E^{1}-3.390247 \times 10^{\circ} E^{2}+8.1678712 \times 10^{-2} E^{3}$ for $1225 \sim 1632^{\circ} \mathrm{C}$ and the maximum error is $5.319723 \times 10^{-2}{ }^{\circ} \mathrm{C}$

$T=1.182817 \times 10^{2} E^{1}-8.76886 \times 10^{-1} E^{2}-1.506577 \times 10^{-1} E^{3}+1.211935 \times 10^{-2} E^{4} \quad$ for

$1633 \sim 1696^{\circ} \mathrm{C}$ and the maximum error is $2.370372 \times 10^{-2}{ }^{\circ} \mathrm{C}$

$T=6.934563 \times 10 E^{1}+5.308651 \times 10^{0} E^{2}-2.204555 \times 10^{-1} E^{3}+4.066083 \times 10^{-3} E^{4} \quad$ for $1670 \sim 1767^{\circ} \mathrm{C}$ and the maximum error is $1.877535 \times 10^{-1}{ }^{\circ} \mathrm{C}$

Based on the curve fitting for Platinum Rhodium 10- Platinum thermocouple with Least Square Method the fitting formula of temperature with thermoelectric emf of thermocouple has been obtained. The maximum error is less than $0.1^{\circ} \mathrm{C}$. 


\section{Conclusion}

This paper introduces a design scheme, meeting problem in the implementation, and the solving method. The scheme is intelligent design scheme of circuit system for temperature measurement and controlling by single chip microcomputer STM32F407 as kernel in steel furnace. It has extensive practical value. The temperature measurement range is $0^{\circ} \mathrm{C} \sim 1800^{\circ} \mathrm{C}$, the measurement precision is $1{ }^{\circ} \mathrm{C}$, and the maximum error is less than $0.1{ }^{\circ} \mathrm{C}$ after the test results are analyzed. Based on the performance indexes the measurement and controlling system of temperature for furnace has reached the advanced level of similar to the products at home and abroad.

\section{Acknowledgments}

This authors would like to thank the support of the open issue in State Key Laboratory of satellite Ocean Environment Dynamics (Second Institute of Oceanophaphy, SOA) (SOED1503).

\section{References}

1. Li Xiaofan, Yao Genghe. The temperature controlling technology of high precision. Radio Technology. 1: 35-36(2005).

2. Wang Min. Temperature controlling instrument of heat treatmen [J]. Electric Drive Automation. 3: 21-24(2007).

3. Chen Jinhua. The intelligent instrument design of temperature controlling system in resistance furnace and its application. Master degree dissertation of Jiangsu University. (2007).

4. Wan Xuejun, Liu Bu. Idea of realizing in solid relay instead of AC contactor based on single chip microcomputer. Digital Technology and application . 4: 24-25(2013).

5. Huang Yu-Hang, Zhu Wei-Hua, Jiang Hong, Jiang Xing-Fang, Design of the Circuit in a Portable Tracing Instrument Based on GPS Technology[J]. International Journal of Application or Innovation in Engineering \& Management. 1(2): 109-113(2012). 